\title{
Association Between Preoperative Vitamin D Status and Short-Term Physical Performance after Total Hip Arthroplasty: A Prospective Study
}

\author{
Edith Visser $^{\mathrm{a}}$ Nicole M. de Roos ${ }^{\mathrm{a}}$ Ellen Oosting $^{\mathrm{b}}$ Silvia C. Endenburg ${ }^{\mathrm{c}}$ \\ Jaap J. Dronkers ${ }^{\text {b }}$ \\ ${ }^{a}$ Division of Human Nutrition, Wageningen University, Wageningen, The Netherlands; ${ }^{b}$ Department of Physical \\ Therapy, Gelderse Vallei Hospital, Ede, The Netherlands; ' Department of Clinical Chemistry and Hematology, \\ Gelderse Vallei Hospital, Ede, The Netherlands
}

\section{Keywords}

Total hip arthroplasty $\cdot$ Hip replacement $\cdot$ Vitamin D $\cdot 25$-Hydroxyvitamin $\mathrm{D}_{3}$. Physical performance . Osteoarthritis · Handgrip strength · Physical activity

\begin{abstract}
Background: Insufficient serum vitamin D concentrations (50-75 nmol/L) are prevalent in $40-65 \%$ of patients who require total hip arthroplasty (THA). This could impair physical recovery after surgery. This study investigated the association between preoperative vitamin $D$ status and physical performance after THA. Additionally, postoperative changes in vitamin $D$ concentrations were measured. Methods: We included 87 patients scheduled for elective THA and aged $\geq 65$ years. Three groups were recruited: patients classified as vitamin $D$ deficient ( $<50 \mathrm{nmol} / \mathrm{L}, n=23$ ), insufficient (50$75 \mathrm{nmol} / \mathrm{L}, n=32$ ), or sufficient ( $>75 \mathrm{nmol} / \mathrm{L}, n=32$ ). Serum 25-hydroxyvitamin $\mathrm{D}_{3}\left(25[\mathrm{OH}] \mathrm{D}_{3}\right)$ concentration and physical performance were measured perioperatively. Linear
\end{abstract}

\begin{tabular}{ll}
\hline KARGER & $\begin{array}{l}\text { (c) } 2018 \text { The Author(s) } \\
\text { Published by S. Karger AG, Basel }\end{array}$ \\
E-Mail karger@karger.com & This article is licensed under the Creative Commons Attribution- \\
www.karger.com/anm & $\begin{array}{l}\text { NonCommercial-NoDerivatives 4.0 International License (CC BY- } \\
\text { NC-ND) (http://www.karger.com/Services/OpenAccessicense). } \\
\text { Usage and distribution for commercial purposes as well as any dis- } \\
\text { tribution of modified material requires written permission. }\end{array}$
\end{tabular}

mixed models were used to examine differences between groups. Results: Change in physical performance over time was not affected by preoperative vitamin D status. In contrast, for physical activity, both vitamin $D(p=0.021)$ and time ( $p<0.001$ ) effect was seen: from $80.2 \pm 25.8$ to $58.1 \pm$ $17.8 \mathrm{~min} /$ day in the deficient group, $143.7 \pm 19.8$ to $92.9 \pm$ $11.5 \mathrm{~min} /$ day in the insufficient group, and $108.1 \pm 20.9$ to $62.3 \pm 12.9 \mathrm{~min} /$ day in the sufficient group. The Chair Stand Test, Timed Up and Go test, and 10-Meter Walking Test also improved significantly over time, but independent of vitamin D status. An increase in $25(\mathrm{OH}) \mathrm{D}_{3}$ concentration 6 weeks postoperatively was correlated with improved hip function (Pearson's $r=-0.471, p=0.018)$. Overall, serum $25(\mathrm{OH}) \mathrm{D}_{3}$ declined with $32 \%$ one day after surgery $(p<0.001)$, to nearly return to baseline values 6 weeks later in all groups. Conclusion: Vitamin D status did not appear to affect physical recovery after THA. The drop in vitamin D after surgery deserves further investigation, but could possibly be explained by hemodilution.

(c) 2018 The Author(s)

Published by S. Karger AG, Basel 


\section{Introduction}

Hip prostheses are increasingly applied, due to an ageing population. In 2014, 189 hip replacement surgeries were performed per 100,000 habitants in Europe [1]. The number of surgeries increased with $25 \%$ between 2000 and 2009 and this trend will continue in the next decades [2].

Total hip arthroplasty (THA) is the surgical procedure to replace the hip joint in patients with osteoarthritis or hip fracture. THA has a high success rate and provides pain relief, improvement of physical functioning, and better health-related quality of life [3-5]. Postoperative recovery of THA is mainly determined by muscle function around the hip [4].

Vitamin D is positively associated with muscle function, muscle strength, and physical performance [6-8]. Furthermore, a meta-analysis of 13 RCTs reported a beneficial effect of vitamin D supplementation (800$100 \mathrm{IU} /$ day) on measures of muscle strength and balance in individuals aged 60 years and older [9]. A metaanalysis of 30 RCTs in individuals of all ages showed a significant positive effect of vitamin D supplementation on muscle strength, which was most evident in people with a 25 -hydroxyvitamin $\mathrm{D}_{3}\left(25[\mathrm{OH}] \mathrm{D}_{3}\right)$ level $<30 \mathrm{nmol} / \mathrm{L}$ and in those who were older than 65 years [10]. Vitamin D plays a direct role on muscle quality via activation of the vitamin $\mathrm{D}$ receptors, which are involved in muscle protein synthesis and muscle growth $[6,8]$. Moreover, vitamin D is indirectly related to muscle function via the calcium-phosphate balance $[6,8]$. Calcium is involved in the contraction of muscle, whereas phosphate is required for the structural and metabolic needs of the muscle cell $[6,11]$. Hence, preoperative vitamin D status might be an important factor of recovery after surgery.

Serum $25(\mathrm{OH}) \mathrm{D}_{3}$ is the main circulating vitamin $\mathrm{D}$ metabolite and is commonly used to determine the vitamin D status [12]. According to the Clinical Practice Guidelines of the Endocrine Society, vitamin D sufficiency is defined as serum $25(\mathrm{OH}) \mathrm{D}_{3}>75 \mathrm{nmol} / \mathrm{L}$ and deficiency as serum $25(\mathrm{OH}) \mathrm{D}_{3}<50 \mathrm{nmol} / \mathrm{L}$ [13]. Previous studies showed that $40-65 \%$ of THA patients had vitamin $\mathrm{D}$ insufficiency, of which $8.5-30 \%$ were vitamin D deficient $[4,14,15]$. Among Dutch elderly (aged $>70$ years), the prevalence of vitamin D insufficiency is $34.8 \%$ in men and $24.9 \%$ in women, whereas a vitamin $\mathrm{D}$ deficiency is present in $44.8 \%$ of men and in $60.1 \%$ of women [16]. Previous studies showed that a low vitamin D status was correlated with poor postoperative hip scores, an increased length of hospital stay and increased risk of postoperative complications [15, 17-19]. However, preoperative vitamin $\mathrm{D}$ concentration was not associated to in-hospital functional milestones and postoperative functional status $[4,14]$. These inconclusive results emphasize the need for further research, which is worthwhile since a deficiency is easy to correct by supplementation.

In contrast to previous studies, the present study will determine both preoperative and postoperative serum $25(\mathrm{OH}) \mathrm{D}_{3}$ concentrations The aim is to describe changes in vitamin D status after THA in osteoarthritic patients and to investigate the association between preoperative vitamin D status and postoperative physical performance.

\section{Methods}

For this research, data from the SpierVit Study was used. This was a prospective cohort study, approved by the Medical Ethics Committee of the Wageningen University, the Netherlands (dossier 11/28, NL40002.081.12). The study started in September 2012 and lasted until July 2013. Patients aged $\geq 65$ years and scheduled for elective THA (not acute surgery) were recruited at hospital Gelderse Vallei, the Netherlands. Exclusion criteria were the presence of dementia or severe heart diseases. Patients were followed from 6 weeks before to 6 weeks after surgery, with 4 measurement points (Fig. 1).

The primary study outcomes were vitamin D status and physical performance. To define vitamin D status, blood samples were drawn during the first visit at the outpatient clinic and analysed by the laboratory of hospital Gelderse Vallei, using high-performance liquid chromatography. Participants were classified as vitamin D deficient $(<50 \mathrm{nmol} / \mathrm{L})$, insufficient $(50-75 \mathrm{nmol} / \mathrm{L})$, or sufficient $(>75 \mathrm{nmol} / \mathrm{L})$ and recruitment was continued until all groups had sufficient numbers to ensure a wide variation in vitamin D status [13].

Physical performance was determined with measurements of muscle strength, muscle power, physical mobility, gait speed, physical activity, and hip function. Preoperative measurements took place 6 weeks before surgery at the physiotherapy department. Muscle strength was assessed with the handgrip strength test, using the Jamar Hydraulic Hand Dynamometer. Three consecutive measurements of the dominant hand were recorded. The maximum strength effort was used for data analysis. Muscle power of the lower extremities was assessed by the Chair Stand Test (CST), which measures the time to complete 10 sequential stand-ups from a chair, without using the handrails [20-22]. The Timed Up and Go test (TUG) was used to determine physical mobility [23], whereas the 10-Meter Walking Test (10MWT) was used as a measure of gait speed [24]. The TUG and 10MWT were performed twice; only the fastest score was used for analysis. Physical activity and household activities over the past 2 weeks were self-reported by patients using the LASA Physical Activity Questionnaire (LAPAQ) [25]. Physical activity was de- 


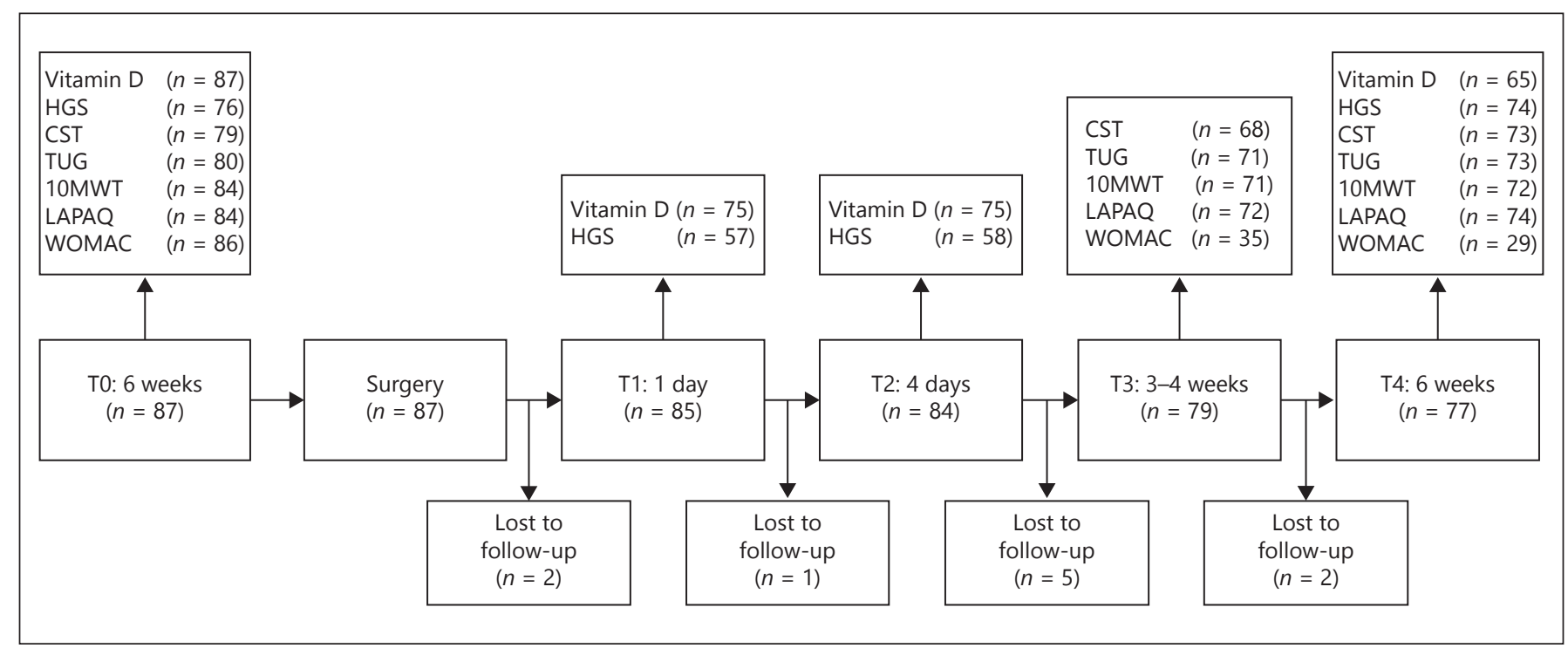

Fig. 1. Flow diagram of SpierVit Study, including number of observations per outcome. 10MWT, 10-meter walking test; CST, chair stand test; HGS, hand grip strength; LAPAQ, LASA physical activity questionnaire; TUG, timed up and go test; WOMAC, Western Ontario and McMaster Universities Osteoarthritis index.

fined as total activity time per day (min/day). Hip function was determined using a validated Dutch version of the Western Ontario and McMaster Universities Osteoarthritis index (WOMAC) [26]. This is a self-reported questionnaire to assess hip function and level of disability [27]. Lower scores indicate better hip function. Measurements of vitamin D and physical performance were repeated at different time points after surgery (Fig. 1).

Demographic characteristics, including age, gender, BMI, and comorbidities were collected from a general questionnaire. Sunlight exposure and vitamin D supplementation were self-reported via a short survey. Postoperative variables were length of hospital stay, need for physical therapy either by a physiotherapist or in a nursing facility, and complications. These were collected from the patient's medical records. Hematocrit levels before and after surgery were used as a marker for hemodilution.

\section{Statistical Analysis}

A sample size of 60 patients was required to detect a difference of $4 \mathrm{~kg}$ in handgrip strength between the 3 vitamin D groups, with $80 \%$ power and a significance level of 0.05 , using an SD of $6 \mathrm{~kg}$ from an unpublished pilot study in patients undergoing abdominal surgery. We also calculated the required number of participants to detect a correlation of 0.3 between vitamin $\mathrm{D}$ and handgrip strength as statistically significant, which was $67[28,29]$. Therefore, by taking a $10 \%$ loss to follow-up into account, the SpierVit Study planned to recruit 25 participants per group.

Baseline characteristics were compared among the 3 vitamin D groups, using ANOVA for parametric variables, Kruskal-Wallis test for non-parametric variables, and Pearson chi-square test for categorical variables.

Because of the multilevel structure of the data, linear mixed models were used to investigate differences between vitamin D groups over time. An unstructured covariance matrix was used to describe changes in serum $25(\mathrm{OH}) \mathrm{D}_{3}$ concentrations over time, with vitamin $\mathrm{D}$ groups, time and their interaction included as fixed effects, and subjects as random effect. In a second model, changes in serum $25(\mathrm{OH}) \mathrm{D}_{3}$ concentrations were adjusted for vitamin $\mathrm{D}$ supplementation and season of blood collection.

To investigate the association between preoperative vitamin $\mathrm{D}$ status and physical performance, the included fixed effects were vitamin $\mathrm{D}$ groups, time, and their interaction, with the covariates gender, age, BMI, length of hospital stay, and physical therapy. Selection of these confounders was based on baseline demographics and results of previous studies [17, 30]. A subject was included in the linear mixed model analysis when at least one measurement of the outcome was present. When a subject had a missing value in one of the fixed effects, the subject was excluded from analysis. A first-order ante-dependence covariance matrix was used for the outcomes CST, TUG, 10MWT, and WOMAC. For the outcomes handgrip strength test and LAPAQ, the heterogeneous compound symmetry matrix was applied. These covariance matrixes were determined by the likelihood ratio test. Post-hoc analyses were performed using a Bonferroni correction.

The Pearson correlation coefficient ( $\mathrm{r}$ ) was calculated between the change in serum $25(\mathrm{OH}) \mathrm{D}_{3}$ concentrations and the change in outcomes of physical performance between baseline and 6 weeks after surgery. This was done for the complete study sample and for men and women separately, since gender is a strong predictor of physical performance. To check whether changes in vitamin $\mathrm{D}$ were due to hemodilution, the correlation ( $\mathrm{r}$ ) between changes in serum $25(\mathrm{OH}) \mathrm{D}_{3}$ concentrations and hematocrit values from baseline to 1 day after surgery were also computed.

Results are presented as mean \pm SEM, unless otherwise stated. A $p$ value $<0.05$ was regarded as statistically significant. Statistical analysis was performed using SPSS version 22 (SPSS Inc., Chicago, IL, USA). 
Table 1. Demographic and clinical characteristics in patients undergoing THA

\begin{tabular}{|c|c|c|c|c|c|}
\hline & \multirow[t]{2}{*}{$n^{\mathrm{a}}$} & \multirow[t]{2}{*}{ Total } & \multicolumn{3}{|c|}{ Vitamin D status } \\
\hline & & & $\begin{array}{l}\text { deficient } \\
<50 \mathrm{nmol} / \mathrm{L}\end{array}$ & $\begin{array}{l}\text { insufficient } \\
50-75 \mathrm{nmol} / \mathrm{L}\end{array}$ & $\begin{array}{l}\text { sufficient } \\
>75 \mathrm{nmol} / \mathrm{L}\end{array}$ \\
\hline Number of patients & & $87(100)$ & $23(26.4)$ & $32(36.8)$ & $32(36.8)$ \\
\hline Gender, female & & $66(75.9)$ & $19(82.6)$ & $21(65.6)$ & $26(81.3)$ \\
\hline Age, years & & $74(68-79)$ & $76(71-82)$ & $72(68-77)$ & $74(67-79)$ \\
\hline $\mathrm{BMI}^{\mathrm{b}}, \mathrm{kg} / \mathrm{m}^{2}$ & & $26(24-28)$ & $27(26-29)$ & $27(24-29)$ & $25(23-26)$ \\
\hline Comorbidities, yes & 80 & $54(67.5)$ & $14(70.0)$ & $22(73.3)$ & $18(60.0)$ \\
\hline Surgery type & 85 & & & & \\
\hline THA & & $27(31.8)$ & $9(39.1)$ & $11(34.4)$ & $7(23.3)$ \\
\hline THA AMIS & & $53(62.4)$ & $12(52.2)$ & $19(59.4)$ & $22(73.3)$ \\
\hline Other & & $5(5.9)$ & $2(8.7)$ & $2(6.3)$ & $1(3.3)$ \\
\hline Physical therapy, yes & 85 & $18(21.2)$ & $6(28.6)$ & $3(9.4)$ & $9(28.1)$ \\
\hline $25(\mathrm{OH}) \mathrm{D}_{3}{ }^{\mathrm{c}}, \mathrm{nmol} / \mathrm{L}$ & & $68.1 \pm 30.11$ & $33.6 \pm 10.18$ & $61.2 \pm 6.73$ & $99.7 \pm 20.79$ \\
\hline Vitamin D supplementation, yes & 75 & $30(40.0)$ & $3(17.6)$ & $14(48.3)$ & $13(44.8)$ \\
\hline
\end{tabular}

Values are presented as mean $\pm \mathrm{SD}$, median (IQR) or $n(\%)$.

${ }^{\mathrm{a}}(n=87)$ unless otherwise specified; ${ }^{\mathrm{b}} p=0.010 ;{ }^{\mathrm{c}} p<0.001$.

THA, total hip arthroplasty; BMI, body mass index; AMIS, anterior minimally invasive surgery; $25(\mathrm{OH}) \mathrm{D}_{3}, 25-\mathrm{hyroxyvitamin} \mathrm{D}_{3}$.

Table 2. Unadjusted outcomes of physical performance at baseline by vitamin D status, in patients undergoing THA

\begin{tabular}{|c|c|c|c|c|c|}
\hline & \multirow[t]{2}{*}{$n$} & \multicolumn{3}{|c|}{ Vitamin D status } & \multirow[t]{2}{*}{$p$ value } \\
\hline & & $\begin{array}{l}\text { deficient } \\
<50 \mathrm{nmol} / \mathrm{L}\end{array}$ & $\begin{array}{l}\text { insufficient } \\
50-75 \mathrm{nmol} / \mathrm{L}\end{array}$ & $\begin{array}{l}\text { sufficient } \\
>75 \mathrm{nmol} / \mathrm{L}\end{array}$ & \\
\hline HGS, kg & 76 & $19.9 \pm 8.90$ & $25.7 \pm 12.37$ & $22.7 \pm 13.78$ & 0.291 \\
\hline CST, s & 79 & $38.1 \pm 13.94$ & $34.8 \pm 16.34$ & $29.4 \pm 9.52$ & 0.081 \\
\hline TUG, s & 80 & $12.6 \pm 5.54$ & $10.8 \pm 3.97$ & $10.4 \pm 4.50$ & 0.226 \\
\hline 10MWT, s & 84 & $13.1 \pm 9.06$ & $10.6 \pm 3.78$ & $9.9 \pm 3.27$ & 0.118 \\
\hline LAPAQ, min/day & 84 & $104.9 \pm 80.23$ & $147.7 \pm 149.0$ & $120.2 \pm 67.28$ & 0.337 \\
\hline WOMAC, scale 0-96 & 86 & $43.5 \pm 16.49$ & $44.2 \pm 16.62$ & $43.5 \pm 15.88$ & 0.981 \\
\hline
\end{tabular}

Values are presented as mean \pm SD.

THA, total hip arthroplasty; HGS, hand grip strength; CST, chair stand test; TUG, timed up and go test; 10MWT, 10-meter walking test; LAPAQ, LASA Physical Activity Questionnaire; WOMAC, Western Ontario and McMaster Universities Osteoarthritis index.

\section{Results}

A total of 87 patients met the inclusion criteria and signed informed consent (Fig. 1). At baseline, 23 patients had vitamin $\mathrm{D}$ deficiency, 32 patients had vitamin $\mathrm{D}$ insufficiency, and 32 patients were vitamin $\mathrm{D}$ sufficient (Table 1 ), with a mean $\pm \mathrm{SD}$ serum $25(\mathrm{OH}) \mathrm{D}_{3}$ concentration of $33.6 \pm 10.2,61.2 \pm 6.7$, and $99.7 \pm 20.8 \mathrm{nmol} / \mathrm{L}$, respectively $(p<0.001)$. Participants were predominantly female $(76 \%)$ and had a median age of 74 years (interquartile range 68-79 years). Table 2 shows the baseline outcomes of physical performance.
Ten participants were lost to follow-up: 4 participants of the deficient group and 3 participants each from the insufficient and sufficient group. Reasons for dropping out differed; 1 participant was hospitalised due to respiratory failure and 1 participant refused follow-up measurements because of personal circumstances, the rest was unknown.

Serum $25(\mathrm{OH}) \mathrm{D}_{3}$ concentrations dropped after surgery but nearly returned to baseline values in all 3 vitamin D groups ( $\mathrm{p}_{\mathrm{vitD}}{ }_{\text {time }}<0.001$, Fig. 2 ). In the post-hoc analysis, serum $25(\mathrm{OH}) \mathrm{D}_{3}$ concentrations were remarkably lower 1 day after surgery compared to base- 


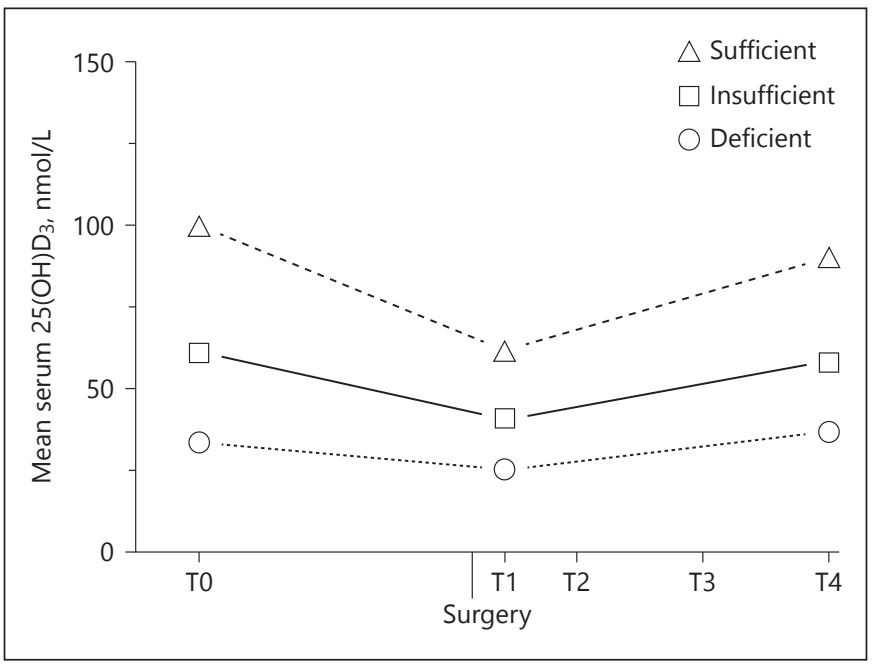

Fig. 2. Vitamin D concentrations at baseline (T0) and postoperative at 1 day (T1), 4 days (T2), and 6 weeks (T4) after THA in 87 osteoarthritic patients. The change in $25(\mathrm{OH}) \mathrm{D}_{3}$ concentrations over time was significantly different between the 3 vitamin $\mathrm{D}$ groups ( $\mathrm{p}_{\text {vitD }}{ }^{*}$ time $\left.<0.001\right) .25(\mathrm{OH}) \mathrm{D}_{3}, 25$-hydroxyvitamin $\mathrm{D}_{3}$.

line ( $\mathrm{p}_{\text {time }}<0.001$ for all 3 groups), with a decrease of $25.0 \%$ for the deficient group, $33.4 \%$ for the insufficient group, and $38.1 \%$ for the sufficient group. Although hematocrit levels dropped as well from $0.42 \pm 0.0038 \mathrm{~L} / \mathrm{L}$ preoperatively to $0.34 \pm 0.0036 \mathrm{~L} / \mathrm{L} 1$ day after surgery $(p<0.001)$, this change was not correlated with the change in serum $25(\mathrm{OH}) \mathrm{D}_{3}$ concentrations $(r=-0.050$, $p=0.669)$. Between the first and fourth day after surgery, serum $25(\mathrm{OH}) \mathrm{D}_{3}$ concentrations increased in all 3 groups and 6 weeks after surgery, they returned to baseline values for the deficient and insufficient group. However, the sufficient vitamin D group had still significantly lower values compared to baseline $\left(\mathrm{p}_{\text {time }}=\right.$ 0.011). Adjusting for vitamin D supplementation and season of blood collection did not affect the outcomes (data not shown).

Table 3 reports the results of the linear mixed model analysis. The interaction term between vitamin $\mathrm{D}$ and time was not statistically significant for any of the outcomes, indicating that the change over time was not significantly different between the 3 vitamin $\mathrm{D}$ groups. Table 4 presents the correlation between the change in serum $25(\mathrm{OH}) \mathrm{D}_{3}$ concentration and changes in physical performance.

At baseline, the insufficient vitamin $\mathrm{D}$ group had the highest mean \pm SD handgrip strength and the deficient group the lowest; $25.7 \pm 12.4 \mathrm{~kg}$ versus $19.9 \pm 8.9 \mathrm{~kg}$ ( $p=$ $0.291)$. However, 6 weeks after surgery, the 3 groups had a comparable handgrip strength and no significant differences were observed either between the vitamin $\mathrm{D}$ groups $\left(\mathrm{p}_{\mathrm{vitD}}=0.322\right)$ or between time points $\left(\mathrm{p}_{\text {time }}=0.143\right)$. In men, the change in handgrip strength was moderately associated with the change in serum $25(\mathrm{OH}) \mathrm{D}_{3}$ concentration, though not significant $(r=0.392, p=0.234)$.

There was neither a vitamin $D^{*}$ time effect for the outcomes CST $\left(\mathrm{p}_{\mathrm{vitD}}{ }^{*}{ }_{\text {time }}=0.411\right), \mathrm{TUG}\left(\mathrm{p}_{\mathrm{vitD}}{ }^{*}{ }_{\text {time }}=0.426\right)$ and 10MWT ( $\left.\mathrm{p}_{\text {vitD }}{ }^{*}{ }_{\text {time }}=0.485\right)$, though all vitamin $\mathrm{D}$ groups performed significantly better on these tests 6 weeks after surgery compared to baseline. Post-hoc analyses showed that 6 weeks postoperatively, the patients needed on average $5.4 \pm 1.73$ seconds less to complete the CST test ( $\left.p_{\text {time }}=0.007\right), 1.6 \pm 0.47$ seconds less for the TUG test ( $\mathrm{p}_{\text {time }}=0.004$, Fig. 3 ), and $2.6 \pm 0.62$ seconds less to complete the 10MWT test ( $\mathrm{p}_{\text {time }}<0.001$ ). Since the 3 lines are more or less parallel, the change over time is not dependent on the preoperative vitamin $\mathrm{D}$ status. The correlation coefficients between the change in serum $25(\mathrm{OH}) \mathrm{D}_{3}$ concentration and the change over time for these 3 tests were all low and insignificant (Table 4).

Although the interaction term was not significant for the LAPAQ questionnaire $\left(\mathrm{p}_{\mathrm{vitD}}{ }^{*}\right.$ time $\left.=0.896\right)$, Figure 4 shows that physical activity was both different between groups and between time points $\left(\mathrm{p}_{\mathrm{vitD}}=0.021\right.$, $\left.\mathrm{p}_{\text {time }}<0.001\right)$. Overall, the insufficient vitamin D group was most physically active. Compared to baseline, the physical activity 4 weeks after surgery was reduced with $60 \%$ to $57.2 \pm 9.7 \mathrm{~min} /$ day for the insufficient group and with $74 \%$ to $28.4 \pm 11.6 \mathrm{~min} /$ day for the sufficient group. Participants with vitamin $\mathrm{D}$ deficiency had a decline of $72 \%$ to $22.1 \pm 16.2 \mathrm{~min} /$ day. Between 4 and 6 weeks after surgery, all groups became significantly more physically active, although levels were still lower compared to baseline.

With regard to hip function, there was a significant inverse association between the change in WOMAC score and the change in serum $25(\mathrm{OH}) \mathrm{D}_{3}$ concentration $(r=-0.471, p=0.018)$. This means that an increase in serum $25(\mathrm{OH}) \mathrm{D}_{3}$ concentration was associated with lower WOMAC scores and thus enhanced hip function 6 weeks after surgery.

\section{Discussion}

In this study, vitamin D status before hip surgery was not associated with physical performance after surgery. However, physical performance significantly improved 
Table 3. Physical performance at baseline (T0) and postoperative at 1 day (T1), 4 days (T2), 3-4 weeks (T3), and 6 weeks (T4) after THA

\begin{tabular}{|c|c|c|c|c|c|c|}
\hline Time points & \multicolumn{3}{|c|}{ Vitamin D status } & \multicolumn{3}{|l|}{$p$ value } \\
\hline HGS, kg & & & & 0.482 & 0.322 & 0.143 \\
\hline T0 & $23.4 \pm 2.14$ & $26.2 \pm 1.57$ & $25.7 \pm 1.74$ & & & \\
\hline $\mathrm{T} 4$ & $26.0 \pm 2.13$ & $27.1 \pm 1.60$ & $25.7 \pm 1.76$ & & & \\
\hline CST, s & & & & 0.411 & 0.836 & $0.010^{c}$ \\
\hline T0 & $32.4 \pm 3.45$ & $33.6 \pm 2.50$ & $28.6 \pm 2.76$ & & & \\
\hline $\mathrm{T} 3$ & $28.3 \pm 2.97$ & $29.8 \pm 1.91$ & $29.4 \pm 2.17$ & & & \\
\hline $\mathrm{T} 4$ & $25.6 \pm 3.20$ & $25.6 \pm 2.06$ & $27.0 \pm 2.26$ & & & \\
\hline TUG, s & & & & 0.426 & 0.574 & $<0.001^{\mathrm{c}, \mathrm{d}}$ \\
\hline T0 & $12.6 \pm 1.23$ & $11.0 \pm 0.98$ & $10.0 \pm 1.03$ & & & \\
\hline $\mathrm{T} 3$ & $10.0 \pm 0.67$ & $9.6 \pm 0.40$ & $10.0 \pm 0.46$ & & & \\
\hline $\mathrm{T} 4$ & $9.1 \pm 0.63$ & $8.1 \pm 0.38$ & $8.6 \pm 0.42$ & & & \\
\hline LAPAQ, min/day & & & & 0.896 & $0.021^{\mathrm{a}}$ & $<0.001^{b, c, d}$ \\
\hline T0 & $80.2 \pm 25.85$ & $143.7 \pm 19.82$ & $108.1 \pm 20.86$ & & & \\
\hline $\mathrm{T} 3$ & $22.1 \pm 16.18$ & $57.2 \pm 9.70$ & $28.4 \pm 11.64$ & & & \\
\hline $\mathrm{T} 4$ & $58.1 \pm 17.80$ & $92.9 \pm 11.52$ & $62.3 \pm 12.89$ & & & \\
\hline WOMAC, scale 0-96 & & & & 0.910 & 0.559 & $<0.001^{\mathrm{b}, \mathrm{c}}$ \\
\hline T0 & $40.3 \pm 4.01$ & $42.5 \pm 2.99$ & $42.8 \pm 3.17$ & & & \\
\hline $\mathrm{T} 3$ & $4.9 \pm 3.64$ & $10.1 \pm 1.90$ & $8.9 \pm 2.37$ & & & \\
\hline $\mathrm{T} 4$ & $3.6 \pm 4.50$ & $6.3 \pm 2.19$ & $7.4 \pm 2.55$ & & & \\
\hline
\end{tabular}

Values are presented as mean \pm SEM.

Linear mixed model analysis, adjusted for gender, age, BMI, length of hospital stay and the need for physiotherapy.

THA, total hip arthroplasty; HGS, hand grip strength; CST, chair stand test; TUG, timed up and go test; 10MWT, 10-meter walking test; LAPAQ, LASA Physical Activity Questionnaire; WOMAC, Western Ontario and McMaster Universities Osteoarthritis index. Posthoc analyses, corrected for multiple comparison with Bonferroni: ${ }^{\mathrm{a}} p<0.05$, deficient vs insufficient; ${ }^{\mathrm{b}} p<0.001$, T0 vs. T3; ${ }^{\mathrm{c}} p<0.01$, T0 vs. T4; ${ }^{\mathrm{d}} p<0.001, \mathrm{~T} 3$ vs. T4.

Table 4. Pearson correlation coefficients between change in serum $25(\mathrm{OH}) \mathrm{D}_{3}$ concentration and change in outcomes of physical performance between baseline and 6 weeks after surgery

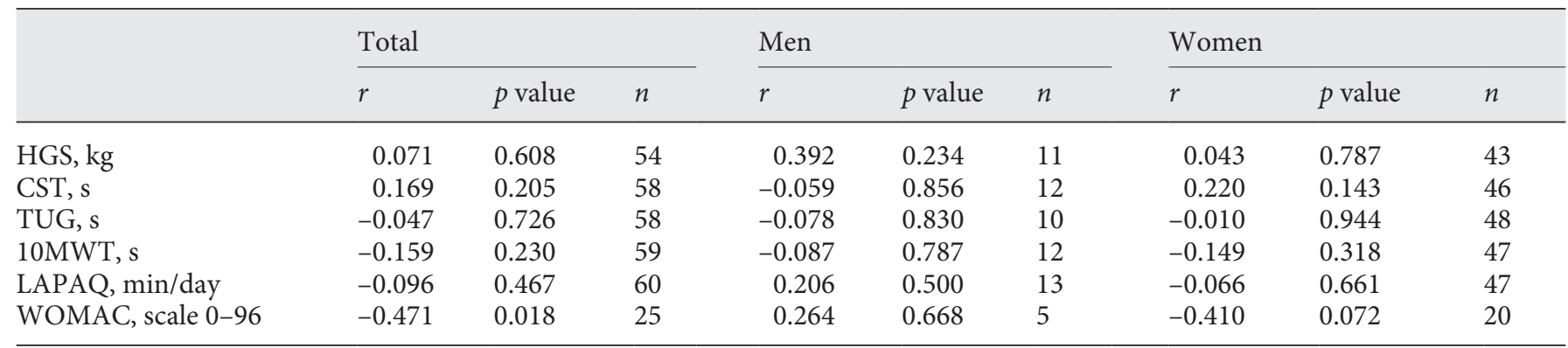

25(OH) $\mathrm{D}_{3}, 25$-hydroxyvitamin $\mathrm{D}_{3}$; HGS, hand grip strength; CST, chair stand test; TUG, timed up and go test; 10MWT, 10-meter walking test; LAPAQ, LASA Physical Activity Questionnaire; WOMAC, Western Ontario and McMaster Universities Osteoarthritis index. 


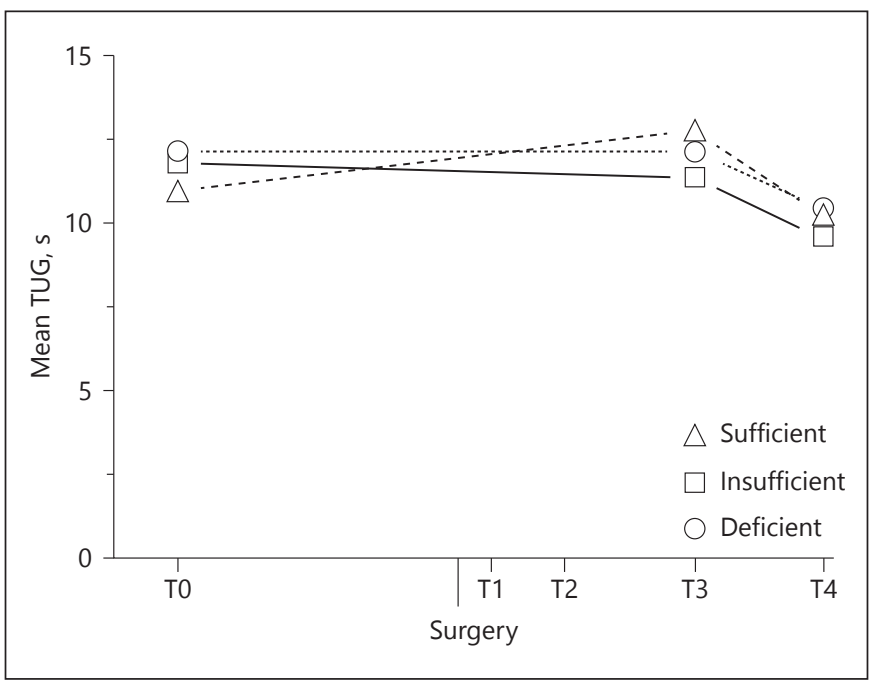

Fig. 3. Physical mobility at baseline (T0) and 3-4 weeks (T3) and 6 weeks (T4) after THA in 82 osteoarthritic patients. Significant difference between $\mathrm{T} 0$ and $\mathrm{T} 4\left(\mathrm{p}_{\text {time }}<0.01\right)$ and between $\mathrm{T} 3$ and T4 $\left(\mathrm{p}_{\text {time }}<0.001\right)$. TUG, Timed Up and Go test.

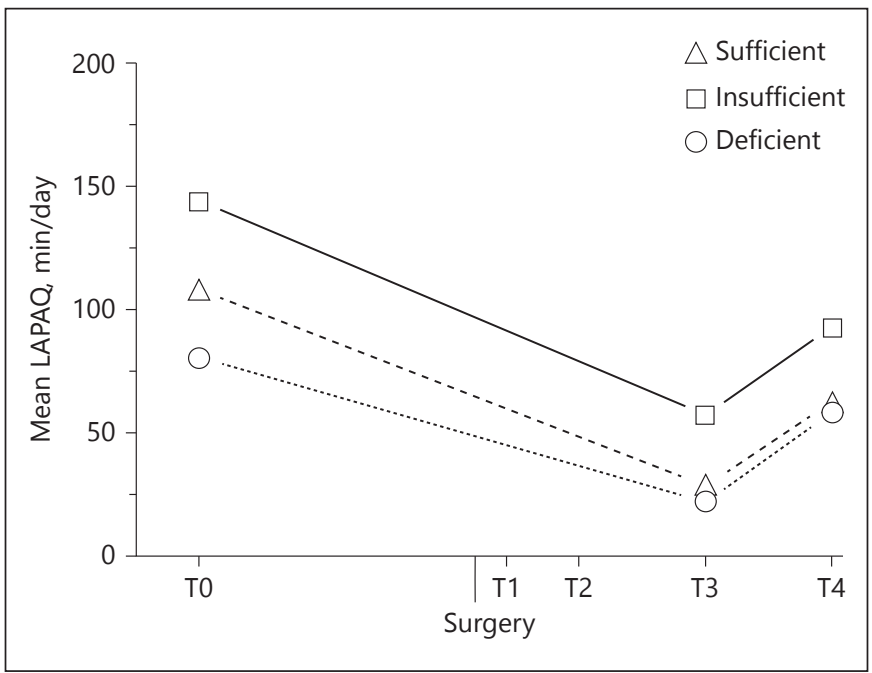

Fig. 4. Physical activity at baseline (T0) and 3-4 weeks (T3) and 6 weeks (T4) after THA in 84 osteoarthritic patients. Significant difference between the deficient and insufficient vitamin $\mathrm{D}$ group $\left(\mathrm{p}_{\mathrm{vitD}}<0.05\right)$ and between each time point $\left(\mathrm{p}_{\text {time }}<0.001\right)$. LAPAQ, LASA Physical Activity Questionnaire.

after THA with increase in muscle power, physical mobility, gait speed, and hip function. Furthermore, we observed a remarkable drop in vitamin $\mathrm{D}$ in the first 4 days after THA, which was gradually restored to baseline values 6 weeks later. To the best of our knowledge, this was the first study that investigated the association between changes in vitamin $\mathrm{D}$ with changes in physical performance.

The decrease in serum $25(\mathrm{OH}) \mathrm{D}_{3}$ concentrations one day after surgery ranged from $25 \%$ to $38 \%$. We hypothesized that this could be due to hemodilution. Although blood hematocrit concentrations were decreased in many patients, changes in hematocrit concentrations did not correlate with changes in serum $25(\mathrm{OH}) \mathrm{D}_{3}$ concentrations. However, during follow-up, hematocrit values restored to baseline values as did the vitamin D concentrations. Therefore, we propose that hemodilution has caused the drop in serum $25(\mathrm{OH}) \mathrm{D}_{3}$ concentrations one day after surgery. However, several other studies have observed a similar decrease in vitamin D. In a study among 40 American patients who required THA, the serum $25(\mathrm{OH}) \mathrm{D}_{3}$ concentrations decreased with $21-34 \%$ the day after surgery, unrelated to changes in fluid balance [31]. They hypothesized that the intracellular uptake of $25(\mathrm{OH}) \mathrm{D}_{3}$ is increased after surgery due to a higher demand for tissue regeneration. Other potential mechanisms are an increased volume of distribution, catabolism, and clearance of vitamin D in the blood [31]. A study among 30 British patients suggested that the urinary loss of the vitamin $\mathrm{D}$-binding protein (VDBP) could explain observed reductions in serum $25(\mathrm{OH}) \mathrm{D}_{3}$ concentrations $48 \mathrm{~h}$ after hip or knee replacement surgery [32]. However, the authors also reported that the urinary loss of VDBP was relatively small and therefore unlikely to have significantly contributed to the decrease in serum $25(\mathrm{OH}) \mathrm{D}_{3}$ concentrations. Unfortunately, we cannot check whether decreases in VDBP were also seen in our study.

Several observational studies have focused on preoperative vitamin D status and outcomes of physical performance after THA. Low vitamin D status was associated with a longer hospital stay in 1,083 German patients after either hip or knee arthroplasty [17]. Two other studies observed a positive association between serum $25(\mathrm{OH}) \mathrm{D}_{3}$ concentrations and pre- and postoperative hip scores [15, 18]. A study of 219 American THA patients had comparable measures as our study [14]. They assessed physical functioning through questionnaires, including the WOMAC, and via 2 performance-based tests, including the TUG. In line with our results, WOMAC scores were significantly improved after 6 weeks follow-up $(p<0.001)$, but irrespective of vitamin D status, which they divided in low $(<75 \mathrm{nmol} / \mathrm{L})$ and normal (>75 nmol/L). The change in the TUG did not differ between the 2 groups, likewise in our study. Lastly, a study among 110 Brazilian patients also found that gait speed 
recovered after THA but unrelated to serum $25(\mathrm{OH}) \mathrm{D}_{3}$ concentrations [33], which corresponded with our results.

A major strength of our study was the use of performance-based tests to determine the physical performance of patients. Other comparable studies mainly used questionnaires and disease-specific scores $[15,18]$, but these are more prone to bias by socially desirable responses and misinterpretation.

Furthermore, a sample size calculation was done prior to recruitment. A sample size of 60 patients divided over the 3 groups was required. To account for dropouts, we included 87 participants, and in the end, 10 participants were lost to follow-up. We optimized the use of available data with the linear mixed model analysis to ensure that our study was not underpowered.

We started recruitment based on the classification of The Institute of Medicine, defining serum $25(\mathrm{OH}) \mathrm{D}_{3}$ $<30 \mathrm{nmol} / \mathrm{L}$ as deficient and $>50 \mathrm{nmol} / \mathrm{L}$ as sufficient [34]. Though, such low concentrations were not highly prevalent in our population and it would have required a much longer recruitment period than expected. Therefore, we switched to the classification of the Endocrine Society, shortly after recruitment started. Possibly, only the vulnerable patients with low concentrations of serum $25(\mathrm{OH})$ $\mathrm{D}_{3}(<30 \mathrm{nmol} / \mathrm{L})$ might benefit from preoperative vitamin D supplementation. Therefore, future studies should focus on this group. A sensitivity analysis was however not possible in our study, due to the low number of patients with a $25(\mathrm{OH}) \mathrm{D}_{3}$ concentration below $30 \mathrm{nmol} / \mathrm{L}$ $(n=7)$.

Recruitment started in September, when serum $25(\mathrm{OH}) \mathrm{D}_{3}$ concentrations were still relatively high due to the seasonal influence. The patients recruited from January until March were mostly classified as vitamin D deficient. The season of surgery could affect the willingness of patients to go out and be active and therefore influence recovery. This could have biased the effect of the already low vitamin D status. However, results did not differ after correction for season of blood collection in the statistical analysis.

Furthermore, both a standard and minimally invasive procedure of THA was performed, of which the latter involves less muscle injury [35]. This might have influenced postoperative performance, but the type of surgery did not differ significantly between the 3 groups. In the first weeks after surgery, patients were ambulant but they were still recovering and some required physical therapy. This explains the almost absence of physical activity 4 weeks postoperatively. The physical activity question- naire clearly showed that recovery started between 4 and 6 weeks, as physical activity improved then. The same holds for the TUG test, which only showed a significant improvement between 4 and 6 weeks after surgery. Therefore, the follow-up time might have been too short to find significant differences between the 3 vitamin D groups.

Due to the observational nature of this study, confounders had to be taken into account. The BMI was significantly lower in the sufficient group and the insufficient group had more men and a lower age. Furthermore, some participants received professional physical therapy after surgery, while others did not. Although we corrected for these variables, we could not completely eliminate the variation between the groups.

We performed this observational study to see if an intervention study with vitamin $\mathrm{D}$ supplementation would be prudent. An association between vitamin D and physical performance was not found in our study, but this could be due to the influence of confounders. However, previous observational studies have found adverse associations between a low vitamin D status and physical outcomes after THA $[15,17,18]$, and a randomized clinical trial can elucidate this effect, with potentially large effects for public health. Vitamin D supplementation is already recommended among elderly people and has a low burden, is inexpensive, safe, and effective in raising serum $25(\mathrm{OH}) \mathrm{D}_{3}$ concentrations in adults [36]. Therefore, a randomized clinical trial can be considered for future research and currently a feasibility study is conducted by another research group [37].

In conclusion, preoperative vitamin $\mathrm{D}$ status was not associated with improved physical performance after THA. Furthermore, serum $25(\mathrm{OH}) \mathrm{D}_{3}$ concentrations were remarkably decreased in the first 4 days after surgery - possibly due to hemodilution - and might therefore not reflect a patient's common vitamin D status. Therefore, the serum $25(\mathrm{OH}) \mathrm{D}_{3}$ concentration should be assessed before surgery to determine the level of deficiency and the need of supplementation. A randomized controlled trial with high doses of vitamin D supplementation could give more insight in the role of vitamin D on physical performance and muscle function after THA.

\section{Disclosure Statement}

The authors have no conflicts of interest to declare. 


\section{References}

1 OECD: "Hip and Knee Replacement", in health at a glance: Europe 2016: State of Health in the eu Cycle. Paris, OECD Publishing, 2016.

2 Holzwarth U, Cotogno G: Total Hip Arthroplasty: State of the Art, Prospects and Challenges, JRC Scientific and policy reports, 2012.

3 Buirs LD, Van Beers LW, Scholtes VA, Pastoors T, Sprague S, Poolman RW: Predictors of physical functioning after total hip arthroplasty: a systematic review. BMJ Open 2016; 6:e010725.

4 Unnanuntana A, Rebolledo BJ, Gladnick BP, Nguyen JT, Sculco TP, Cornell CN, Lane JM: Does vitamin $d$ status affect the attainment of in-hospital functional milestones after total hip arthroplasty? J Arthroplasty 2012;27:482489.

5 Forster-Horvath C, Egloff C, Valderrabano V, Nowakowski AM: The painful primary hip replacement - review of the literature. Swiss Med Wkly 2014;144:w13974.

6 Ceglia L, Harris SS: Vitamin D and its role in skeletal muscle. Calcif Tissue Int 2013;92: 151-162.

7 Halfon M, Phan O, Teta D: Vitamin D: A review on its effects on muscle strength, the risk of fall, and frailty. Biomed Res Int 2015;2015: 953241.

8 Minshull C, Biant LC, Ralston SH, Gleeson N: A systematic review of the role of vitamin $d$ on neuromuscular remodelling following exercise and injury. Calcif Tissue Int 2016;98:426-437.

9 Muir SW, Montero-Odasso M: Effect of vitamin d supplementation on muscle strength, gait and balance in older adults: a systematic review and meta-analysis. J Am Geriatr Soc 2011;59:2291-2300.

10 Beaudart C, Buckinx F, Rabenda V, Gillain S, Cavalier E, Slomian J, Petermans J, Reginster $\mathrm{JY}$, Bruyère $\mathrm{O}$ : The effects of vitamin $\mathrm{d}$ on skeletal muscle strength, muscle mass, and muscle power: a systematic review and metaanalysis of randomized controlled trials. J Clin Endocrinol Metab 2014;99:4336-4345.

11 Girgis CM, Clifton-Bligh RJ, Hamrick MW, Holick MF, Gunton JE: The roles of vitamin d in skeletal muscle: form, function, and metabolism. Endocr Rev 2012;34:33-83.

12 Zerwekh JE: Blood biomarkers of vitamin D status. Am J Clin Nutr 2008;87:1087S-1091S.

13 Holick MF, Binkley NC, Bischoff-Ferrari HA, Gordon CM, Hanley DA, Heaney RP, Murad $\mathrm{MH}$, Weaver CM: Evaluation, treatment, and prevention of vitamin d deficiency: an endocrine society clinical practice guideline. J Clin Endocrinol Metab 2011;96:1911-1930.

14 Unnanuntana A, Saleh A, Nguyen JT, Sculco TP, Cornell CN, Mancuso CA, Lane JM: Low vitamin d status does not adversely affect short-term functional outcome after total hip arthroplasty. J Arthroplasty 2013;28:315-322. e312.

15 Lavernia CJ, Villa JM, Iacobelli DA, Rossi MD: Vitamin D insufficiency in patients with THA: prevalence and effects on outcome. Clin Orthop Relat Res 2014;472:681-686.

16 Boonman-de Winter L, Albersen A, Mohrmann K, Bakx-van Baal C, Meijer Timmerman Thijssen D, Bressers J: [High prevalence of vitamin D deficiency in the southwest Netherlands]. Ned Tijdschr Geneeskd 2015;159:A8167.

17 Maier GS, Maus U, Lazovic D, Horas K, Roth $\mathrm{KE}$, Kurth AA: Is there an association between low serum 25-oh-d levels and the length of hospital stay in orthopaedic patients after arthroplasty? J Orthop Traumatol 2016; 17:297-302.

18 Nawabi DH, Chin KF, Keen RW, Haddad FS: Vitamin d deficiency in patients with osteoarthritis undergoing total hip replacement: a cause for concern? J Bone Joint Surg Br 2010; 92:496-499.

19 Traven S, Chiaramonti A, Barfield W, Kirkland P, Demos H, Del Schutte H, Drew J: Fewer complications following revision hip and knee arthroplasty in patients with normal vitamin D levels. J Arthroplasty 2017; 32(9 suppl):S193-S196.

20 Csuka M, McCarty DJ: Simple method for measurement of lower extremity muscle strength. Am J Med 1985;78:77-81.

21 Bassey EJ, Fiatarone MA, O'neill EF, Kelly M, Evans WJ, Lipsitz LA: Leg extensor power and functional performance in very old men and women. Clin Sci (Lond) 1992;82:321-327.

22 Md JFB, Kiely DK, Herman S, Leveille SG, Mizer K, Frontera WR, Fielding RA: The relationship between leg power and physical performance in mobility-limited older people. J Am Geriatr Soc 2002;50:461-467.

23 Podsiadlo D, Richardson S: The timed "up \& go": a test of basic functional mobility for frail elderly persons. J Am Geriatr Soc 1991;39: 142-148.

24 Leerar PJ, Miller EW: Concurrent validity of distance-walks and timed-walks in the wellelderly. J Geriatr Phys Ther 2002;25:3-6.

25 Stel VS, Smit JH, Pluijm SM, Visser M, Deeg DJ, Lips P: Comparison of the lasa physical activity questionnaire with a 7-day diary and pedometer. J Clin Epidemiol 2004;57:252258.

26 Roorda L, Jones C, Waltz M, Lankhorst G, Bouter L, Van der Eijken J, Willems W, Heyligers I, Voaklander D, Kelly K: Satisfactory cross cultural equivalence of the dutch womac in patients with hip osteoarthritis waiting for arthroplasty. Ann Rheum Dis 2004;63: 36-42.

27 Bellamy N, Buchanan WW, Goldsmith $\mathrm{CH}$, Campbell J, Stitt LW: Validation study of womac: A health status instrument for measuring clinically important patient relevant outcomes to antirheumatic drug therapy in patients with osteoarthritis of the hip or knee. J Rheumatol 1988;15:1833-1840.

28 Janssen HC, Samson MM, Verhaar HJ: Muscle strength and mobility in vitamin d-insufficient female geriatric patients: a randomized controlled trial on vitamin $\mathrm{d}$ and calcium supplementation. Aging Clin Exp Res 2010;22: 78-84.

29 Mowé M, Haug E, Bøhmer T: Low serum calcidiol concentration in older adults with reduced muscular function. J Am Geriatr Soc 1999;47:220-226.

30 Goula T, Kouskoukis A, Drosos G, Tselepis A-S, Ververidis A, Valkanis C, Zisimopoulos A, Kazakos K: Vitamin d status in patients with knee or hip osteoarthritis in a mediterranean country. J Orthop Traumatol 2015;16: 35-39.

31 Binkley N, Coursin D, Krueger D, Iglar P, Heiner J, Illgen R, Squire M, Lappe J, Watson $\mathrm{P}$, Hogan K: Surgery alters parameters of vitamin $\mathrm{d}$ status and other laboratory results. Osteoporos Int 2016:1-8.

32 Waldron JL, Ashby HL, Cornes MP, Bechervaise J, Razavi C, Thomas OL, Chugh S, Deshpande S, Ford C, Gama R: Vitamin D: a negative acute phase reactant. J Clin Pathol 2013; 66:620-622.

33 da Cunha BM, Gava AD, de Oliveira SB, de David AC, Dos Santos-Neto LL: Vitamin d is related to gait recovery after total hip arthroplasty: a prospective analysis. Gait Posture 2016;50:96-101.

34 Ross AC, Taylor CL, Yaktine AL, Del Valle HB: Dietary Reference Intakes for Adequacy: Calcium and Vitamin D, 2011.

35 Siddiqui N, Mohandas P, Muirhead-Allwood S, Nuthall T: A review of minimally invasive hip replacement surgery-current practice and the way forward. Curr Orthop 2005; 19:247254.

36 Vieth R, Chan PC, MacFarlane GD: Efficacy and safety of vitamin $\mathrm{d} 3$ intake exceeding the lowest observed adverse effect level. Am J Clin Nutr 2001;73:288-294.

37 Morrison RJ, Bunn D, Gray WK, Baker PN, White C, Rangan A, Rankin KS, Reed MR: Vaso (vitamin d and arthroplasty surgery outcomes) study - supplementation of vitamin d deficiency to improve outcomes after total hip or knee replacement: study protocol for a randomised controlled feasibility trial. Trials 2017; 18:514 